Review

\title{
Defining Molecular Sensors to Assess Long-Term Effects of Pesticides on Carcinogenesis
}

\author{
Fanny L'Héritier ${ }^{1, \dagger}$, Maud Marques ${ }^{1, \dagger}$, Myriam Fauteux ${ }^{1}$ and Luc Gaudreau ${ }^{1, *}$ \\ Département de Biologie, Université de Sherbrooke, 2500 boul. de l'Université, Sherbrooke, \\ QC J1K 2R1, Canada; E-Mails: Fanny.Lheritier@USherbrooke.ca (F.L.); \\ Maud.Marques@USherbrooke.ca (M.M.); Myriam.Fauteux@USherbrooke.ca (M.F.) \\ $\dagger$ These authors contributed equally to this work. \\ * Author to whom correspondence should be addressed; E-Mail: Luc.Gaudreau@Usherbrooke.ca; \\ Tel.: +1-819-821-8000 (ext. 62081).
}

Received: 3 July 2014; in revised form: 11 September 2014 / Accepted: 22 September 2014 /

Published: 25 September 2014

\begin{abstract}
The abundance of dioxins and dioxin-like pollutants has massively increased in the environment due to human activity. These chemicals are particularly persistent and accumulate in the food chain, which raises major concerns regarding long-term exposure to human health. Most dioxin-like pollutants activate the aryl hydrocarbon receptor (AhR) transcription factor, which regulates xenobiotic metabolism enzymes that belong to the cytochrome P450 1A family (that includes CYP1A1 and CYP1B1). Importantly, a crosstalk exists between estrogen receptor $\alpha(E R \alpha)$ and AhR. More specifically, ER $\alpha$ represses the expression of the CYPIA1 gene, which encodes an enzyme that converts $17 \beta$-estradiol into 2-hydroxyestradiol. However, $(\mathrm{ER} \alpha)$ does not repress the $C Y P 1 B 1$ gene, which encodes an enzyme that converts $17 \beta$-estradiol into 4-hydroxyestradiol, one of the most genotoxic estrogen metabolites. In this review, we discuss how chronic exposure to xenobiotic chemicals, such as pesticides, might affect the expression of genes regulated by the $\mathrm{AhR}-\mathrm{ER} \alpha$ crosstalk. Here, we focus on recent advances in the understanding of molecular mechanisms that mediate this crosstalk repression, and particularly on how ER $\alpha$ represses the AhR target gene CYP1A1, and could subsequently promote breast cancer. Finally, we propose that genes implicated in this crosstalk could constitute important biomarkers to assess long-term effects of pesticides on human health.
\end{abstract}


Keywords: aryl hydrocarbon receptor (AhR); ER $\alpha$; pesticides

\section{Introduction}

The aryl hydrocarbon receptor (AhR) is a ligand-activated transcription factor that belongs to the basic helix-loop-helix (bHLH)/Per-Arnt-Sim (PAS) family [1]. It is maintained inactive in the cytoplasm in a complex with the Hsp90-XAP2-p23 chaperones [2]. Activation of AhR occurs via direct binding of its ligands, where it translocates into the nucleus to form a complex with the bHLH/PAS Arnt protein. This heterodimer complex then binds regulatory consensus regions termed xenobiotic response elements (XREs) located at proximity to its target genes, which include the phase I detoxifying monooxygenases CYPIA1 and CYPIB1 [3]. The best-characterized AhR ligands commonly fall into the following classes: halogenated aromatic hydrocarbons (HAHs), such as 2,3,7,8-tetra chlorodibenzo- $p$-dioxin (TCDD), polycyclic aromatic hydrocarbons (PAHs) and polychlorinated biphenyls (PCBs) [4]. All these chemicals are human by-products that emanate from human-based activities. For example, high levels of PAHs are found in barbecue cooked meat, and are becoming a major concern for human health considering their persistence in the environment.

$\mathrm{AhR}$ is best known for its role as a mediator of toxicity during environmental pollutant metabolism. However, recent studies show that AhR plays an important role in normal physiology and development as well [5-9]. There has also been various studies demonstrating interactions and crosstalk between $\mathrm{AhR}$ and various intracellular signaling pathways, including NF- $\mathrm{B}$ [10,11], Nrf2 [12], Rb/E2F [13], and Sp1 [14], as well as other transcription factors belonging to the nuclear receptor family, such as the androgen receptor [15], and the estrogen receptors (ER $\alpha$ and ER $\beta$ ) [15-19]. The crosstalk between the signaling pathways of $\mathrm{AhR}$ and $\mathrm{ER} \alpha$ receptors will be the main focus of this review, especially in the context of breast cancer development.

$\mathrm{AhR}$ is proposed to have a role in breast development in utero, during pregnancy and also as previously mentioned, in breast cancer initiation. The mammary gland is composed of different cell types and structures that are subject to change during various and specific life stages, i.e., puberty and pregnancy. Consequently, exposure to AhR agonists could have different outcomes making it challenging to show direct effects of pollutants on breast cancer incidence. Several studies reported higher AhR expression in more malignant breast cancer cell lines as well as a positive correlation with breast tumors aggressiveness [20,21]. However, another study showed that $72.7 \%$ of benign mammary tissues have nuclear AhR immunohistochemistry staining [22]. The two main target genes of AhR in breast tissues are CYP1A1 and CYP1B1. CYP1A1 mRNA and protein levels are low in normal and breast tumor tissues. However, higher CYP1B1 mRNA and protein levels are observed in breast tumors as compared to normal tissues.

\section{Ligands and Agonists of Aryl Hydrocarbon Receptor (AhR)}

The best-characterized high-affinity AhR ligands are hydrophobic molecules that bear aromatic carbon rings. However, there is more and more evidence suggesting that there is a growing spectrum of structurally diverse chemicals that are capable of binding and/or activating the AhR signaling 
pathway. In this section, well will briefly discuss known endogenous and exogenous ligands of AhR, with an emphasis on pesticides.

\section{Endogenous Ligands}

Human exposure to toxic environmental chemicals has greatly changed in the last 200 years, especially in societies struck by the industrial revolution. On the one hand, this suggests that AhR has probably been the target of recent evolutionary pressure in various species. One example recently published by Mark Hahn's laboratory [23] showed that Atlantic tomcod from the Hudson River exposed to high level of PCB, released by General Electric facilities, exhibited a variant of the AHR2 gene, which is absent in nearly all tomcod from elsewhere. This variant possesses less affinity for TCDD and others AhR ligands, and consequently has less transcriptional activity and toxicity. On the other hand, it is reasonable to assume that AhR response to these man-made chemicals is a sign of biochemical versatility of the receptor to bind a wide range of molecules (see below). This, in turn, may suggest that AhR could also respond to various endogenous ligands, i.e., produced by the cells themselves. Studies showing that the AhR signaling pathway is active in the absence of exogenous ligands have reinforced this view, and lead scientists to suspect a role for AhR in physiological functions of cells. Consequently, intensification of research to find endogenous AhR ligands has sparked over the last few years. The following chemicals, which are endogenously synthesized by human tissues, are known activators of AhR: indigoids, equilenin, heme metabolites, arachidonic acid metabolites, eicosanoids, and tryptophan derivatives [24-26]. L-Kynurenine, a tryptophan catabolite, was shown to activate AhR and to be constitutively produced by tumor cells, and astonishingly promote their survival and escape from the immune system [27]. The later observations provide new evidence that an endogenous ligand of AhR promotes carcinogenesis, thereby conferring oncogenic properties to AhR.

\section{Exogenous Ligands}

\section{1. "Classical” Synthetic AhR Ligands}

As mentioned earlier, AhR is activated by a large group of environmental pollutants composed of HAHs (including TCDD), PAHs (including benzo[a]pyrene), and PCBs [4]. The majority of these chemicals are formed and released as by-products of human activities, mostly emanating from industrial and combustion processes [28].

\subsection{Natural/Dietary Compounds}

One of the most obvious potential sources of naturally occurring AhR ligands probably comes from our diet. The non-toxic indole-3-carbinol (I3C) and its derivatives, including 3,3'-diindolylmethane (DIM), have been gathering great attention lately for their anticancer properties. However, there are other natural compounds that have been reported to activate the AhR signaling pathway, including flavonoids, carotenoids, curcumin, and others, which are reviewed in Nguyen et al. and Stejskalova et al. [24,26]. 


\subsection{Pesticides}

In depth analysis of a wide range of pesticides currently used in agriculture revealed that many of them possess a structure very similar to well-known AhR ligands, such as TCDD. Considering that exposure to pesticides may lead to various human diseases, including cancer, the implication of AhR in this process should be carefully assessed. It has been documented for quite some time now that pesticides possess endocrine disrupting properties [29]. Several currently used pesticides have been reported to have estrogenic activity [30-36]. Endocrine disruption of the estrogen receptor-signaling pathway can be direct (i.e., chemicals bind the estrogen receptor and modulate its activity) or indirect (i.e., chemicals affect another pathway such as the AhR case, which then modulates ER $\alpha$ activity). More recently, Kojima et al. used in vitro reporter gene assays to screen 200 pesticides for estrogen and androgen activities. They also tested the AhR agonistic activity for these 200 pesticides. Out of those, three herbicides - propanil, linuron and diuron - showed potent AhR agonistic activity and only two - chlorpyrifos and isoxathion — showed both AhR and ER $\alpha$ activities [37,38].

Several studies were able to measure pesticide concentrations in breast cancer biopsies (adipose tissues and tumor sections). As such, Cassidy and collaborators showed that heptachlor epoxide induces nitric oxide production in the breast tissues, which may contribute to tumor initiation by increasing DNA damages in the cells [39]. Another group evaluated breast cancer risk and exposure to environmental estrogens - more specifically, 16 organochlorine pesticides. The authors found that the presence of a higher concentration of the pesticides aldrin and lindane is associated with an increased risk of developing breast cancer, especially for leaner postmenopausal women. [40] All these studies suggest an important role for pesticides and others environmental chemicals in the initiation and development of breast cancer; however, none of the studies thus far elude to mechanisms of action of these chemical, and how they affect the ER $\alpha$ and AhR signaling pathways (or their crosstalk).

Certain pesticides are capable of activating $A h R$ and consequently inducing the expression of CYP1A1 and CYP1B1 genes. The enzymes encoded by these two genes are involved in 17ß-estradiol (E2) metabolism: CYP1A1 and CYP1B1 convert E2 into 2-hydroxyestradiol (2-OHE2) and 4-hydroxyestradiol (4-OHE2), respectively [41,42]. Several studies have compared the tumorigenic potential of E2 and its metabolites, such as 2-OHE2 and 4-OHE2 [43-45]. In fact, 2-OHE2 inhibits cellular growth of breast cancer cell lines [46], and induces apoptosis in immortalized mammary cells [47]. In contrast, 4-OHE2 induces kidney tumors in Syrian hamsters [45], and enhances proliferation and mutagenesis by promoting the formation of depurinated adducts on DNA [48]. 4-OHE2 is reported to be one of the most genotoxic estradiol metabolites. It has also been reported that breast cancer cells metabolize more 4-OHE2 than normal cells [49]. Thus, the ratio between 2-OHE2/4-OHE2 metabolites, and consequently, the ratio between CYP1A1/CYP1B1 enzymes, appears to be important in the initiation of carcinogenesis in mammary tissues. In addition, if some pesticides induce more $C Y P 1 B 1$ expression than $C Y P 1 A 1$, this could also lead to imbalances in the ratio between CYP1A1 and CYP1B1 enzymes. Consequently, if we consider this scenario on a long-term exposure scale, more 4-OHE2 metabolites would be formed, hence leading to the accumulation of DNA adducts and potentially initiating cancer development (Figure 1). Estrogen metabolites have already been established as potential biomarkers for susceptibility to breast cancer [50]. Thus, linking 
pesticide exposure to this imbalanced ratio in favor of the CYP1B1 enzyme would provide direct evidence that pesticides may play a role in the early steps of breast cancer development.

Figure 1. Proposed model for initiation of breast cancer by pollutants and pesticides. Long-term exposure to pollutants and pesticides, which could induce the aryl hydrocarbon receptor $(\mathrm{AhR})$ and the estrogen receptor $\alpha(\mathrm{ER} \alpha)$ signaling pathways, will create an imbalance between CYP1A1 and CYP1B1 enzymes. Thus, this will modify the 2-OHE2/4-OHE2 ratio and could contribute to mammary carcinogenesis.

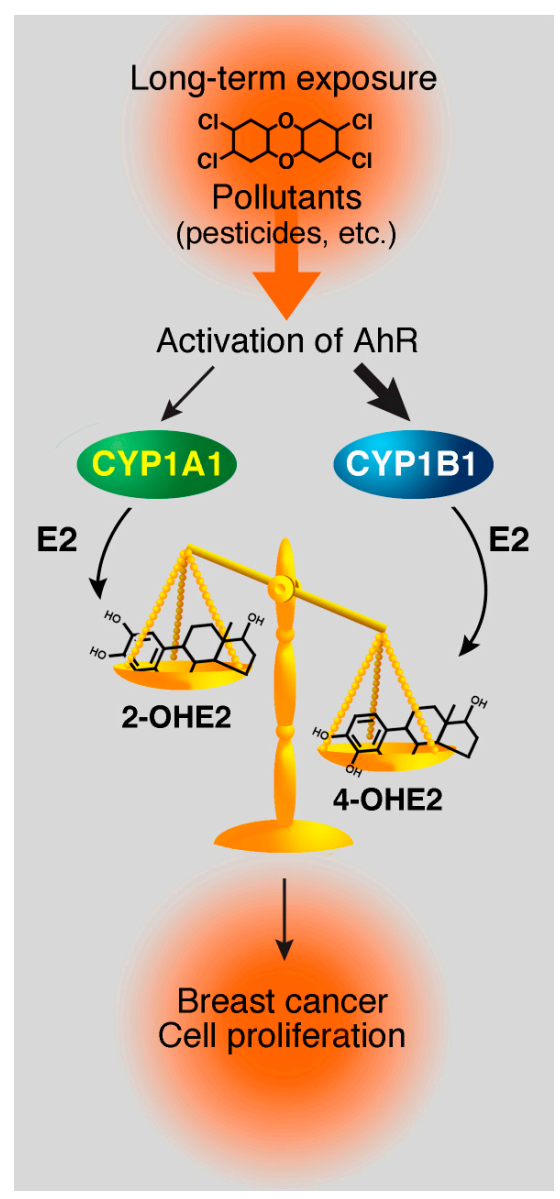

It should also be taken into consideration that some of these pesticides probably contain impurities, and may even be contaminated with dioxins, which could only aggravate their adverse effects. The most notorious example is Agent Orange, an herbicide used during the Vietnam War by the U.S. military as a defoliating product. The now-banned herbicide was a mixture of 2,4-D (2,4-dichloro phenoxyacetic acid) and 2,4,5-T (2,4,5-trichlorophenoxyacetic acid), and it was later shown that 2,4,5-T was contaminated with small amounts of TCDD [51]. In 2004, the latest update of the Veterans and Agent Orange report of the National Academies' Institute of Medicine (IOM) claimed there was enough evidence of an association between exposure to this herbicide and the following illnesses: chronic lymphocytic leukemia, soft-tissue sarcoma, non-Hodgkin's lymphoma, Hodgkin's disease, and chloracne.

While the acute toxicity of pesticides has been well documented, there is still little known about the adverse effects of long-term chronic exposure on human health. According to the World Health Organization (WHO), long-term exposure to pesticides could increase the risk of developmental and 
reproductive disorders, immune-system disruption, endocrine disruption, impaired nervous-system function, and development of certain types of cancers, such as breast cancer [52]. Attempts to establish correlations between the effects of pesticides on human health are particularly difficult because there are known sex, genetic, epigenetic, and environmental differences in the capacity to metabolize xenobiotics. Differences in susceptibility may also be affected by variations in the rate at which the xenobiotics are eliminated from the body. The adverse effects of pesticides may be related to their interactions with AhR, but they may also be partially or totally mediated by an AhR-independent signaling pathway. In both cases, specific windows of exposure to pesticides during a lifetime can have different outcomes thus complicating the interpretation of epidemiological studies. In addition, genetic differences in the properties of AhR are known to exist in human populations, and polymorphisms in cytochrome P450 enzymes have been associated with increased susceptibility to different cancers [53].

Consequently, this demonstrates the challenges as well as the importance of better understanding the mechanisms that underline the crosstalk that exist between dioxin receptor and estrogen receptor signalling, and also rigorously test how different pollutants and pesticides affect this crosstalk.

\section{Molecular Mechanisms of AhR and ERa Crosstalk}

Interaction between the AhR and the ER $\alpha$ signaling pathways has been observed for several years. $\mathrm{ER} \alpha$ belongs to the nuclear receptor family of transcription factors and is involved in the regulation of cellular proliferation in response to E2, for example during mammary gland development [54]. Numerous laboratories have focused their interests in studying the inhibition of the ER $\alpha$ signaling pathway by AhR. However, the role of ER $\alpha$ in the regulation of the expression of AhR target genes is less documented. Firstly, we will review the main conclusions and mechanisms proposed for the regulation of ER $\alpha$ by AhR. Secondly, we will discuss why the study of the differential regulation of AhR target genes (CYP1A1 and CYP1B1) by ER $\alpha$ is important, and why this can influence mammary carcinogenesis.

\section{AhR-Mediated Repression of the ERa Signaling Pathway}

The earliest study to establish a link between pollutants and estrogen-induced cancer was carried out by Kociba and collaborators in 1978 [55]. They made the striking observation that female Sprague-Dawley rats treated with TCDD for two years developed less mammary and uterine tumors than non treated rats [55]. Ten years later, other studies showed that TCDD treatment also inhibits proliferation only in ER $\alpha$ positive breast cancer cell lines, and not in ER $\alpha$ negative cell lines [56,57]. The chemopreventive and chemotherapeutic activities of TCDD in breast carcinogenesis triggered the interest of numerous laboratories to find or to develop AhR agonists that possess the antiestrogenic activity of TCDD, but without its acute toxicity. These AhR agonists are called Selective AhR Modulator (SAhRM). One example of such a SAhRM is the DIM, an acid-catalyzed metabolite of I3C, which is a compound found in cruciferous vegetables. Chen and colleagues showed that female rats treated with DIM had a decrease in E2-dependant 7,12-dimethylbenzanthracene (DMBA)-induced mammary tumors [58]. However, DIM, additionally of AhR activation, also activates ER $\alpha$ by ligand-independent pathways mediated by the PKA and MAPK signaling [59], which could have deleterious effects [60]. 
The regulation of ER $\alpha$ by AhR acts at many levels, for which four different mechanisms have been proposed: firstly, studies showed that $\mathrm{AhR}$ and ER $\alpha$ interact with common transcription factors and coactivators in order to modulate transcription [61-64]. Consequently, when the two pathways are activated simultaneously, AhR and ER $\alpha$ compete for the binding of these factors. Secondly, AhR represses some ER target genes by binding directly their promoter. The first example to document this mechanism was discovered at the cathepsin $D$ promoter where the sequence of the pentanucleotide core of the XRE is found [65,66]. The presence of the inhibitory XRE (iXRE) is necessary for the repression of cathepsin $D$ by AhR. Functional iXREs were later identified in the promoter of $c$-fos, hsp27 and TFF1 genes [67-69]. Thirdly, the activation of AhR increases the degradation of ER $\alpha$ by the ubiquitin-proteasome pathway $[19,70]$. Ohtake and co-workers showed that AhR is associated with an E3-ubiquitine ligase complex, which is proposed to be involved in ER $\alpha$ degradation [15]. Additionally, using an Estrogen response element (ERE) placed upstream of a luciferase reporter, they showed that the presence of MG132 (a proteasome inhibitor) abrogates the repression elicited by AhR in a ligand-specific manner. However, this result is challenged by other studies showing that MG132 affects the mRNA levels of the ER $\alpha$ target genes, even in the absence of AhR ligands [71,72]. The discrepancies between these results raise a major concern regarding data obtained with reporter constructs. Nevertheless, activated-AhR and E2-mediated degradation of ER $\alpha$ borrows two different pathways, which could explain why one is necessary for $\mathrm{ER} \alpha$ target genes expression and the other one inhibits it [15]. Fourthly, in breast cancer cells, TCDD induces the expression of CYP1A1 and $C Y P 1 B 1$, which encode enzymes that convert E2 into catecholestrogens [41,42]. The expression of these enzymes leads to an increase in E2 metabolism and a reduction of intracellular E2 concentration. Although, this mechanism may contribute in the repression of the ER $\alpha$ signaling pathway by AhR, it is not sufficient to explain all the cellular effects that are observed. Indeed, the repression of cathepsin $D$ expression mediated by TCDD occurs very quickly after E2 treatment, and at this time point, CYP1A1 is not yet induced [65]. Moreover, in rats treated with TCDD, the level of E2 circulating in the blood is not affected [73]. In conclusion, the pathway involving E2 metabolizing enzymes is not necessary for the inhibitory crosstalk observed between AhR and ER $\alpha$.

\section{ER $\alpha$-Mediated Repression of AhR Target Genes}

In mammary tissues, $C Y P 1 A 1$ and $C Y P 1 B 1$ are the two most induced AhR target genes after TCDD treatment. As previously mentioned, the enzymes encoded by these two genes are involved in E2 metabolism: CYP1A1 converts E2 in 2-OHE2, while CYP1B1 converts E2 in 4-OHE2, one of the most genotoxic estrogen metabolites. Interestingly, ER $\alpha$ specifically represses $C Y P 1 A 1$ gene expression, but not $C Y P 1 B 1$. We propose that action of ER $\alpha$ may constitute another mechanism by which it promotes carcinogenesis.

Our laboratory has focused efforts to unravel the mechanism(s) involved in the CYP1A1 gene repression by ER $\alpha$ in breast cancer cell lines. We discovered two new key players in the regulation of CYP1A1 expression in ER $\alpha$ positive cell lines: the histone variant H2A.Z and the DNA methyltransferase Dnmt3B. Depletion of H2A.Z in MCF7 cells triggers DNA methylation of AhR binding sites in the CYP1A1 promoter, and thus affects CYP1A1 induction in the presence of AhR agonists. In cell lines which do not express ER $\alpha$, the absence of H2A.Z has no effect on the induction of CYP1A1 [60]. 
Previous work from the Henikoff laboratory showed that H2A.Z antagonizes DNA methylation in Arabidopsis thaliana [74] and a similar conclusion has been drawn in a murine model [75]. The same mechanism appears to be true at the CYP1A1 promoter in the presence of ER $\alpha$. Moreover, we showed that $\mathrm{ER} \alpha$ recruitment to the CYP1A1 promoter in presence of TCDD and E2 decreases AhR binding at its XREs, which leads to two times less induction of CYP1A1 mRNA level than in the presence of TCDD alone. We also discovered that the inhibition of DNA methylation, by either 5-azacytidine treatment or by depleting Dnmt3B, impairs specific inhibition of CYP1A1 by ER $\alpha$ [60]. Taken together, these new findings suggest that DNA methylation plays a central function in the regulation of the CYPIAl expression in the presence of ER $\alpha$. A model is proposed for this mechanism in Figure 2.

Figure 2. Proposed model for the regulation of the $C Y P 1 A 1$ gene by ER $\alpha$. In the absence of estradiol and 2,3,7,8-tetrachlorodibenzo-p-dioxin (TCDD), CYP1A1 is not expressed and H2A.Z is present in its promoter. In the presence of both ligands, H2A.Z is removed and $\mathrm{AhR} / \mathrm{Arnt} / \mathrm{ER} \alpha$ is recruited to the CYPlAl promoter. ER $\alpha$ displaces AhR/Arnt by promoting DNA methylation on the XREs in the CYP1A1 promoter, thus resulting in less AhR activating surfaces available to stimulate $C Y P 1 A 1$ expression than in presence of TCDD alone.
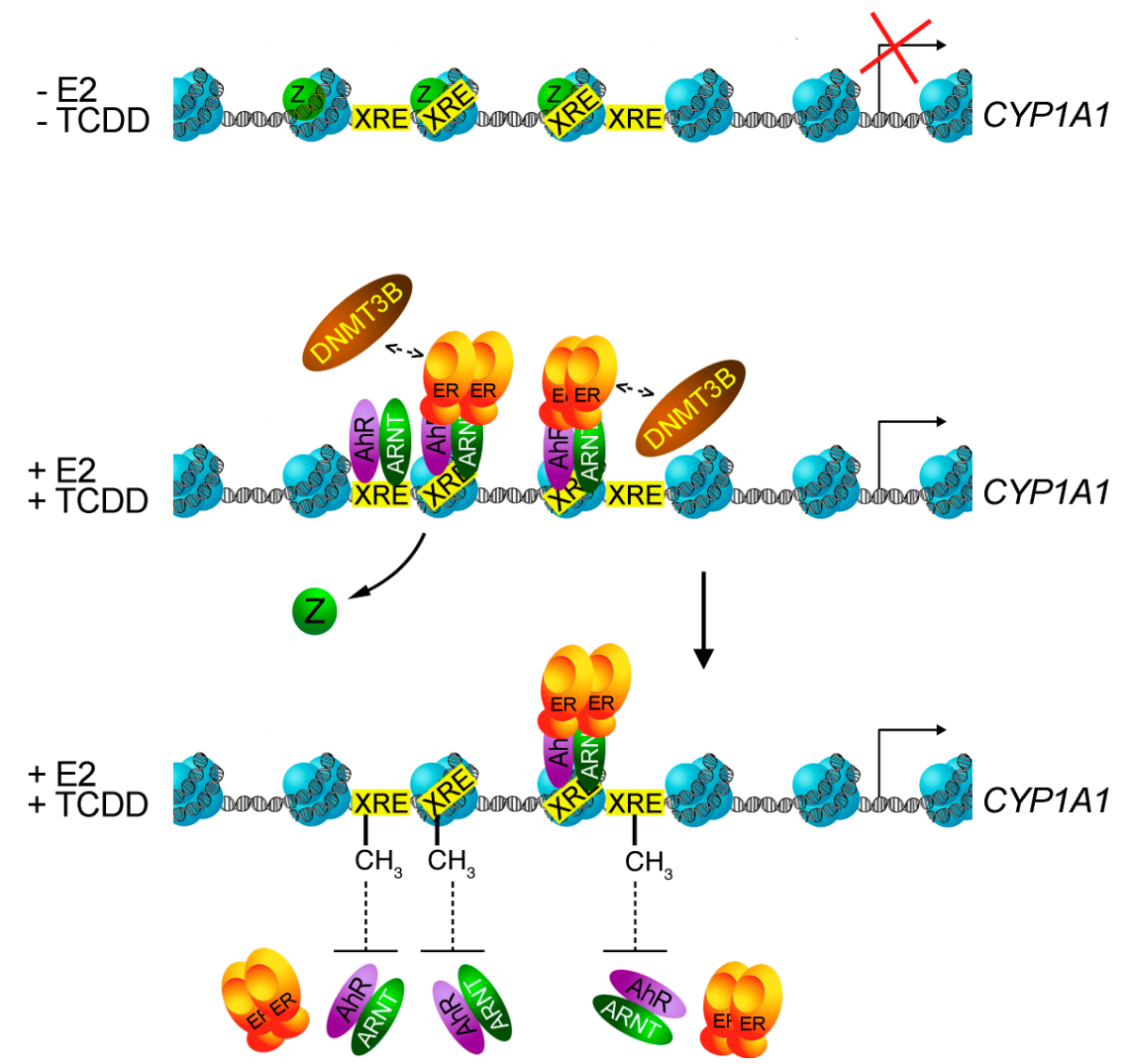

\section{Conclusions}

Industrialized countries generate more and more pesticides and pollutants. However, there is a general concern in fabricating useful chemicals that are not "as toxic" as older generation pesticides. Nonetheless, there is no way to tell how the pesticides used today in our agricultural practices will influence our health on a long-term basis. It is clear that even though a particular pollutant may 
not present a high health risk-probably based on toxicological tests performed with laboratory animals - it may still significantly perturb endocrine systems, and lead to the generation of genotoxic metabolites. We believe that genes involved in the regulation of the crosstalk that exists between the dioxin receptor and estrogen receptor signaling could become important molecular sensors, or biomarkers, to assess potential long-term effects of pesticides on certain forms of cancer.

\section{Acknowledgments}

Work performed in the laboratory of Luc Gaudreau is funded by the Canadian Institutes of Health Research (Ottawa, ON, Canada), the Cancer Research Society (Montreal, QC, Canada), and a Canada Research Chair on Mechanisms of Gene Transcription (Ottawa, ON, Canada). We are grateful to Benoît Guillemette and Jean-François Millau for discussions and critical reading of the manuscript. We also thank Benoît Leblanc for artwork in Figures 1 and 2.

\section{Conflicts of Interest}

The authors declare no conflict of interest.

\section{References}

1. Hankinson, O. The aryl hydrocarbon receptor complex. Annu. Rev. Pharmacol. Toxicol. 1995, 35, 307-340.

2. Kazlauskas, A.; Sundstrom, S.; Poellinger, L.; Pongratz, I. The HSP90 chaperone complex regulates intracellular localization of the dioxin receptor. Mol. Cell. Biol. 2001, 21, 2594-607.

3. Nebert, D.W.; Gonzalez, F.J. P450 genes: Structure, evolution, and regulation. Annu. Rev. Biochem. 1987, 56, 945-993.

4. Poland, A.; Glover, E. Chlorinated biphenyl induction of aryl hydrocarbon hydroxylase activity: A study of the structure-activity relationship. Mol. Pharmacol. 1977, 13, 924-938.

5. Esser, C.; Rannug, A.; Stockinger, B. The aryl hydrocarbon receptor in immunity. Trends Immunol. 2009, 30, 447-454.

6. Linden, J.; Lensu, S.; Tuomisto, J.; Pohjanvirta, R. Dioxins, the aryl hydrocarbon receptor and the central regulation of energy balance. Front. Neuroendocrinol. 2010, 31, 452-478.

7. Stevens, E.A.; Mezrich, J.D.; Bradfield, C.A. The aryl hydrocarbon receptor: A perspective on potential roles in the immune system. Immunology 2009, 127, 299-311.

8. McMillan, B.J.; Bradfield, C.A. The aryl hydrocarbon receptor sans xenobiotics: Endogenous function in genetic model systems. Mol. Pharmacol. 2007, 72, 487-498.

9. Schmidt, J.V.; Su, G.H.; Reddy, J.K.; Simon, M.C.; Bradfield, C.A. Characterization of a murine Ahr null allele: Involvement of the Ah receptor in hepatic growth and development. Proc. Natl. Acad. Sci. USA 1996, 93, 6731-6736.

10. Tian, Y.; Ke, S.; Denison, M.S.; Rabson, A.B.; Gallo, M.A. Ah receptor and NF-кB interactions, a potential mechanism for dioxin toxicity. J. Biol. Chem. 1999, 274, 510-515. 
11. Kim, D.W.; Gazourian, L.; Quadri, S.A.; Romieu-Mourez, R.; Sherr, D.H.; Sonenshein, G.E. The RelA NF-kappaB subunit and the aryl hydrocarbon receptor (AhR) cooperate to transactivate the c-myc promoter in mammary cells. Oncogene 2000, 19, 5498-506.

12. Hayes, J.D.; Dinkova-Kostova, A.T.; McMahon, M. Cross-talk between transcription factors AhR and Nrf2: Lessons for cancer chemoprevention from dioxin. Toxicol. Sci. 2009, 111, 199-201.

13. Puga, A.; Barnes, S.J.; Dalton, T.P.; Chang, C.; Knudsen, E.S.; Maier, M.A. Aromatic hydrocarbon receptor interaction with the retinoblastoma protein potentiates repression of E2F-dependent transcription and cell cycle arrest. J. Biol. Chem. 2000, 275, 2943-2950.

14. Wang, F.; Wang, W.; Safe, S. Regulation of constitutive gene expression through interactions of Sp1 protein with the nuclear aryl hydrocarbon receptor complex. Biochemistry 1999, 38, 11490-11500.

15. Ohtake, F.; Baba, A.; Takada, I.; Okada, M.; Iwasaki, K.; Miki, H.; Takahashi, S.; Kouzmenko, A.; Nohara, K.; Chiba, T.; et al. Dioxin receptor is a ligand-dependent E3 ubiquitin ligase. Nature 2007, 446, 562-566.

16. Beischlag, T.V.; Perdew, G.H. ER $\alpha-A H R-A R N T$ protein-protein interactions mediate estradiol-dependent transrepression of dioxin-inducible gene transcription. J. Biol. Chem. 2005, 280, 21607-21611.

17. Matthews, J.; Wihlen, B.; Thomsen, J.; Gustafsson, J.A. Aryl hydrocarbon receptor-mediated transcription: Ligand-dependent recruitment of estrogen receptor alpha to 2,3,7,8-tetrachloro dibenzo-p-dioxin-responsive promoters. Mol. Cell Biol. 2005, 25, 5317-5328.

18. Ohtake, F.; Takeyama, K.; Matsumoto, T.; Kitagawa, H.; Yamamoto, Y.; Nohara, K.; Tohyama, C.; Krust, A.; Mimura, J.; Chambon, P.; et al. Modulation of oestrogen receptor signalling by association with the activated dioxin receptor. Nature 2003, 423, 545-550.

19. Wormke, M.; Stoner, M.; Saville, B.; Walker, K.; Abdelrahim, M.; Burghardt, R.; Safe, S. The aryl hydrocarbon receptor mediates degradation of estrogen receptor alpha through activation of proteasomes. Mol. Cell Biol. 2003, 23, 1843-1855.

20. Powell, J.B.; Goode, G.D.; Eltom, S.E. The aryl hydrocarbon receptor: A target for breast cancer therapy. J. Cancer Ther. 2013, 4, 1177-1186.

21. Yang, X.; Solomon, S.; Fraser, L.R.; Trombino, A.F.; Liu, D.; Sonenshein, G.E.; Hestermann, E.V.; Sherr, D.H. Constitutive regulation of CYP1B1 by the aryl hydrocarbon receptor (AhR) in pre-malignant and malignant mammary tissue. J. Cell. Biochem. 2008, 104, 402-417.

22. Korzeniewski, N.; Wheeler, S.; Chatterjee, P.; Duensing, A.; Duensing, S. A novel role of the aryl hydrocarbon receptor (AhR) in centrosome amplification - implications for chemoprevention. Mol. Cancer 2010, 9, 153.

23. Wirgin, I.; Roy, N.K.; Loftus, M.; Chambers, R.C.; Franks, D.G.; Hahn, M.E. Mechanistic basis of resistance to PCBs in Atlantic tomcod from the Hudson River. Science 2011, 331, 1322-1325.

24. Stejskalova, L.; Dvorak, Z.; Pavek, P. Endogenous and exogenous ligands of aryl hydrocarbon receptor: Current state of art. Curr. Drug Metab. 2011, 12, 198-212.

25. Denison, M.S.; Nagy, S.R. Activation of the aryl hydrocarbon receptor by structurally diverse exogenous and endogenous chemicals. Annu. Rev. Pharmacol. Toxicol. 2003, 43, 309-334.

26. Nguyen, L.P.; Bradfield, C.A. The search for endogenous activators of the aryl hydrocarbon receptor. Chem. Res. Toxicol. 2008, 21, 102-116. 
27. Opitz, C.A.; Litzenburger, U.M.; Sahm, F.; Ott, M.; Tritschler, I.; Trump, S.; Schumacher, T.; Jestaedt, L.; Schrenk, D.; Weller, M.; et al. An endogenous tumour-promoting ligand of the human aryl hydrocarbon receptor. Nature 2011, 478, 197-203.

28. Marinkovic, N.; Pasalic, D.; Ferencak, G.; Grskovic, B.; Stavljenic Rukavina, A. Dioxins and human toxicity. Arh. Rada. Toksikol. 2010, 61, 445-453.

29. Colborn, T.; vom Saal, F.S.; Soto, A.M. Developmental effects of endocrine-disrupting chemicals in wildlife and humans. Environ. Health Perspect. 1993, 101, 378-384.

30. Welch, R.M.; Levin, W.; Conney, A.H. Estrogenic action of DDT and its analogs. Toxicol. Appl. Pharmacol. 1969, 14, 358-367.

31. Bulger, W.H.; Muccitelli, R.M.; Kupfer, D. Studies on the in vivo and in vitro estrogenic activities of methoxychlor and its metabolites. Role of hepatic mono-oxygenase in methoxychlor activation. Biochem. Pharmacol. 1978, 27, 2417-2423.

32. Cummings, A.M. Methoxychlor as a model for environmental estrogens. Crit. Rev. Toxicol. 1997, 27, 367-379.

33. Coosen, R.; van Velsen, F.L. Effects of the $\beta$-isomer of hexachlorocyclohexane on estrogen-sensitive human mammary tumor cells. Toxicol. Appl. Pharmacol. 1989, 101, 310-318.

34. Soto, A.M.; Sonnenschein, C.; Chung, K.L.; Fernandez, M.F.; Olea, N.; Serrano, F.O. The E-SCREEN assay as a tool to identify estrogens: An update on estrogenic environmental pollutants. Environ. Health Perspect. 1995, 103, 113-122.

35. Garey, J.; Wolff, M.S. Estrogenic and antiprogestagenic activities of pyrethroid insecticides. Biochem. Biophys. Res. Commun. 1998, 251, 855-859.

36. Anderson, H.R. Vinggaard, A.M. Rasmussen, T.H. Gjermandsen, I.M.; Bonefeld-Jorgensen, E.C. Effects of currently used pesticides in assays for estrogenicity, andrenogenicity, and aromatase activity in vitro. Toxicol. Appl. Pharmacol. 2002, 179, 1-12.

37. Takeuchi, S.; Iida, M.; Yabushita, H.; Matsuda, T.; Kojima, H. In vitro screening for aryl hydrocarbon receptor agonistic activity in 200 pesticides using a highly sensitive reporter cell line, DR-EcoScreen cells, and in vivo mouse liver cytochrome P450-1A induction by propanil, diuron and linuron. Chemosphere 2008, 74, 155-165.

38. Kojima, H.; Katsura, E.; Takeuchi, S.; Niiyama, K.; Kobayashi, K. Screening for estrogen and androgen receptor activities in 200 pesticides by in vitro reporter gene assays using Chinese hamster ovary cells. Environ. Health Perspect. 2004, 112, 524-531.

39. Cassidy, R.A.; Natarajan, S.; Vaughan, G.M. The link between the insecticide heptachlor epoxide, estradiol, and breast cancer. Breast Cancer Res. Treat. 2005, 90, 55-64.

40. Ibarluzea Jm, J.; Fernandez, M.F.; Santa-Marina, L.; Olea-Serrano, M.F.; Rivas, A.M.; Aurrekoetxea, J.J.; Exposito, J.; Lorenzo, M.; Torne, P.; Villalobos, M.; et al. Breast cancer risk and the combined effect of environmental estrogens. Cancer Causes Control 2004, 15, 591-600.

41. Martucci, C.P.; Fishman, J. P450 enzymes of estrogen metabolism. Pharmacol. Ther. 1993, 57, $237-257$.

42. Tsuchiya, Y.; Nakajima, M.; Yokoi, T. Cytochrome P450-mediated metabolism of estrogens and its regulation in human. Cancer Lett. 2005, 227, 115-124.

43. Yager, J.D.; Liehr, J.G. Molecular mechanisms of estrogen carcinogenesis. Annu. Rev. Pharmacol. Toxicol. 1996, 36, 203-232. 
44. Newbold, R.R.; Liehr, J.G. Induction of uterine adenocarcinoma in CD-1 mice by catechol estrogens. Cancer Res. 2000, 60, 235-237.

45. Liehr, J.G.; Fang, W.F.; Sirbasku, D.A.; Ari-Ulubelen, A. Carcinogenicity of catechol estrogens in Syrian hamsters. J. Steroid Biochem. 1986, 24, 353-356.

46. Gupta, M.; McDougal, A.; Safe, S. Estrogenic and antiestrogenic activities of 16 $\alpha$ - and 2-hydroxy metabolites of $17 \beta$-estradiol in MCF-7 and T47D human breast cancer cells. J. Steroid Biochem. Mol. Biol. 1998, 67, 413-419.

47. Hurh, Y.J.; Chen, Z.H.; Na, H.K.; Han, S.Y.; Surh, Y.J. 2-Hydroxyestradiol induces oxidative DNA damage and apoptosis in human mammary epithelial cells. J. Toxicol. Environ. Health A 2004, 67, 1939-1953.

48. Zhao, Z.; Kosinska, W.; Khmelnitsky, M.; Cavalieri, E.L.; Rogan, E.G.; Chakravarti, D.; Sacks, P.G.; Guttenplan, J.B. Mutagenic activity of 4-hydroxyestradiol, but not 2-hydroxyestradiol, in BB rat2 embryonic cells, and the mutational spectrum of 4-hydroxyestradiol. Chem. Res. Toxicol 2006, $19,475-479$.

49. Coumoul, X.; Diry, M.; Robillot, C.; Barouki, R. Differential regulation of cytochrome P450 1A1 and 1B1 by a combination of dioxin and pesticides in the breast tumor cell line MCF-7. Cancer Res. 2001, 61, 3942-3948.

50. Rogan, E.G.; Badawi, A.F.; Devanesan, P.D.; Meza, J.L.; Edney, J.A.; West, W.W.; Higginbotham, S.M.; Cavalieri, E.L. Relative imbalances in estrogen metabolism and conjugation in breast tissue of women with carcinoma: Potential biomarkers of susceptibility to cancer. Carcinogenesis 2003, 24, 697-702.

51. Stone, R. Epidemiology. Agent orange's bitter harvest. Science 2007, 315, 176-179.

52. The Health and Environment Linkages Initiative (HELI). Available online: http://www.who.int/ heli/risks/toxics/chemicals/en/index.html (accessed on 23 September 2014).

53. Johansson, I.; Ingelman-Sundberg, M. Genetic polymorphism and toxicology-With emphasis on cytochrome p450. Toxicol. Sci. 2011, 120, 1-13.

54. Hewitt, S.C.; Korach, K.S. Estrogen receptors: Structure, mechanisms and function. Rev. Endocr. Metab. Disord. 2002, 3, 193-200.

55. Kociba, R.J.; Keyes, D.G.; Beyer, J.E.; Carreon, R.M.; Wade, C.E.; Dittenber, D.A.; Kalnins, R.P.; Frauson, L.E.; Park, C.N.; Barnard, S.D.; et al. Results of a two-year chronic toxicity and oncogenicity study of 2,3,7,8-tetrachlorodibenzo-p-dioxin in rats. Toxicol. Appl. Pharmacol. 1978, 46, 279-303.

56. Gierthy, J.F.; Lincoln, D.W., 2nd. Inhibition of postconfluent focus production in cultures of MCF-7 human breast cancer cells by 2,3,7,8-tetrachlorodibenzo-p-dioxin. Breast Cancer Res. Treat. 1988, 12, 227-233.

57. Gierthy, J.F.; Lincoln, D.W.; Gillespie, M.B.; Seeger, J.I.; Martinez, H.L.; Dickerman, H.W.; Kumar, S.A. Suppression of estrogen-regulated extracellular tissue plasminogen activator activity of MCF-7 cells by 2,3,7,8-tetrachlorodibenzo-p-dioxin. Cancer Res. 1987, 47, 6198-6203.

58. Chen, I.; McDougal, A.; Wang, F.; Safe, S. Aryl hydrocarbon receptor-mediated antiestrogenic and antitumorigenic activity of diindolylmethane. Carcinogenesis 1998, 19, 1631-1639. 
59. Leong, H.; Riby, J.E.; Firestone, G.L.; Bjeldanes, L.F. Potent ligand-independent estrogen receptor activation by 3,3'-diindolylmethane is mediated by cross talk between the protein kinase $\mathrm{A}$ and mitogen-activated protein kinase signaling pathways. Mol. Endocrinol. 2004, 18, 291-302.

60. Marques, M.; Laflamme, L.; Gaudreau, L. Estrogen receptor alpha can selectively repress dioxin receptor-mediated gene expression by targeting DNA methylation. Nucleic Acids Res. 2013, 41, 8094-8106.

61. Nguyen, T.A.; Hoivik, D.; Lee, J.E.; Safe, S. Interactions of nuclear receptor coactivator/corepressor proteins with the aryl hydrocarbon receptor complex. Arch. Biochem. Biophys. 1999, 367, 250-257.

62. Kumar, M.B.; Perdew, G.H. Nuclear receptor coactivator SRC-1 interacts with the Q-rich subdomain of the AhR and modulates its transactivation potential. Gene Expr. 1999, 8, 273-286.

63. Kumar, M.B.; Tarpey, R.W.; Perdew, G.H. Differential recruitment of coactivator RIP140 by $\mathrm{Ah}$ and estrogen receptors. Absence of a role for LXXLL motifs. J. Biol. Chem. 1999, 274, 22155-22164.

64. Kobayashi, A.; Numayama-Tsuruta, K.; Sogawa, K.; Fujii-Kuriyama, Y. CBP/p300 functions as a possible transcriptional coactivator of Ah receptor nuclear translocator (Arnt). J. Biochem. 1997, $122,703-710$.

65. Krishnan, V.; Porter, W.; Santostefano, M.; Wang, X.; Safe, S. Molecular mechanism of inhibition of estrogen-induced cathepsin D gene expression by 2,3,7,8-tetrachlorodibenzo- $p$ dioxin (TCDD) in MCF-7 cells. Mol. Cell Biol. 1995, 15, 6710-6719.

66. Wang, F.; Samudio, I.; Safe, S. Transcriptional activation of cathepsin D gene expression by 17 $\beta$-estradiol: Mechanism of aryl hydrocarbon receptor-mediated inhibition. Mol. Cell Endocrinol. 2001, 172, 91-103.

67. Duan, R.; Porter, W.; Samudio, I.; Vyhlidal, C.; Kladde, M.; Safe, S. Transcriptional activation of c-fos protooncogene by 17ß-estradiol: Mechanism of aryl hydrocarbon receptor-mediated inhibition. Mol. Endocrinol. 1999, 13, 1511-1521.

68. Porter, W.; Wang, F.; Duan, R.; Qin, C.; Castro-Rivera, E.; Kim, K.; Safe, S. Transcriptional activation of heat shock protein 27 gene expression by $17 \beta$-estradiol and modulation by antiestrogens and aryl hydrocarbon receptor agonists. J. Mol. Endocrinol. 2001, 26, 31-42.

69. Gillesby, B.E.; Stanostefano, M.; Porter, W.; Safe, S.; Wu, Z.F.; Zacharewski, T.R. Identification of a motif within the 5 ' regulatory region of $\mathrm{pS} 2$ which is responsible for AP-1 binding and TCDD-mediated suppression. Biochemistry 1997, 36, 6080-6089.

70. Harris, M.; Zacharewski, T.; Safe, S. Effects of 2,3,7,8-tetrachlorodibenzo- $p$-dioxin and related compounds on the occupied nuclear estrogen receptor in MCF-7 human breast cancer cells. Cancer Res. 1990, 50, 3579-3584.

71. Lonard, D.M.; Nawaz, Z.; Smith, C.L.; O’Malley, B.W. The $26 \mathrm{~S}$ proteasome is required for estrogen receptor- $\alpha$ and coactivator turnover and for efficient estrogen receptor- $\alpha$ transactivation. Mol. Cell 2000, 5, 939-948.

72. Reid, G.; Hubner, M.R.; Metivier, R.; Brand, H.; Denger, S.; Manu, D.; Beaudouin, J.; Ellenberg, J.; Gannon, F. Cyclic, proteasome-mediated turnover of unliganded and liganded ER $\alpha$ on responsive promoters is an integral feature of estrogen signaling. Mol. Cell 2003, 11, 695-707. 
73. Shiverick, K.T.; Muther, T.F. Effects of 2,3,7,8-tetrachlorodibenzo- $p$-dioxin on serum concentrations and the uterotrophic action of exogenous estrone in rats. Toxicol. Appl. Pharmacol. 1982, 65, 170-176.

74. Zilberman, D.; Coleman-Derr, D.; Ballinger, T.; Henikoff, S. Histone H2A.Z and DNA methylation are mutually antagonistic chromatin marks. Nature 2008, 456, 125-129.

75. Conerly, M.L.; Teves, S.S.; Diolaiti, D.; Ulrich, M.; Eisenman, R.N.; Henikoff, S. Changes in H2A.Z occupancy and DNA methylation during B-cell lymphomagenesis. Genome Res. 2010, 20, 1383-1390.

(C) 2014 by the authors; licensee MDPI, Basel, Switzerland. This article is an open access article distributed under the terms and conditions of the Creative Commons Attribution license (http://creativecommons.org/licenses/by/3.0/). 